\title{
Comparative analysis of various modelling techniques for emission prediction of diesel engine fueled by diesel fuel with nanoparticle additives $^{\S}$
}

\section{Erdi Tosun ${ }^{1 *}$, Tayfun Ozgur ${ }^{2}$, Ceyla Ozgur², Mustafa Ozcanli², Hasan Serin², Kadir Aydin²}

\author{
${ }^{1}$ Çukurova University, Department of Mechanical Engineering, Turkey; etosun@cu.edu.tr \\ ${ }^{2}$ Çukurova University, Department of Automotive Engineering, Turkey; tozgur@cu.edu.tr, kdraydin@cu.edu.tr, ozcanli@cu.edu.tr
}

\begin{abstract}
In this study, emissions of compression ignition engine fueled by diesel fuel with nanoparticle additives was modeled by regression analysis, artificial neural network (ANN) and adaptive neuro fuzzy inference system (ANFIS) methods. Cetane number $(\mathrm{CN})$ and engine speed $(\mathrm{rpm})$ were selected as input parameters for estimation of carbon monoxide (CO), oxides of nitrogen (NOx), and carbon dioxide $\left(\mathrm{CO}_{2}\right)$ emissions. The results of estimation techniques were compared with each other and they showed that regression analysis was not accurate enough for prediction. On the other hand, ANN and ANFIS modelling techniques gave more accurate results with respect to regression analysis; linear and non-linear. Especially ANFIS models can be suggested as estimation method with minimum error compared to experimental results.
\end{abstract}

Keywords: Adaptive neuro fuzzy inference system; Artificial neural network; Diesel engine; Regression analysis

\section{INTRODUCTION}

In recent years, depletion of fossil fuels forces researchers to search new alternative fuels. In literature, there are a lot of studies about fuels which have potential to replace fossil fuels used in internal combustion engines. In this respect, various biofuels and alcohols seem as good option [1]. In addition to scarcity of conventional fuels, efforts on performance en-hancement and emission reduction of engines are the other important issues on which engineers and engine manufacturers are working on it. Especially, the stringent emission legislations enforced manufacturers to develop new technologies [2]. Traditional engine research and development studies are both difficult and costly to meet emission limits imposed by legislations. Therefore, these costly studies are replaced by various cost-effective approaches as artificial neural networks (ANN) and computational fluid dynamics (CFD) [3]. ANNs are nonlinear computer algorithms, which can model the behavior of complex nonlinear processes. Recently, this method has been widely applied to various disciplines as automotive engineering [4]. Yusaf et al. studied the effect of using CPO (crude palm oil) - OD (ordinary diesel) blends as fuel on the performance of CI (compression ignition) engine. In addition, engine power output, fuel consumption, and exhaust-gas emission are evaluated and then predicted using ANN technique [5]. Shanmugam et al. used ANN modeling to predict the performance and exhaust emissions of the diesel engine using hybrid fuel and they revealed that the ANN approach could be confidently used to predict the performance and emissions of the diesel engine accurately [6]. Ghazikhani and Mirzaii predicted soot emission of a waste-gated turbo-charged DI diesel engine using ANN. The results showed the ANN approach can be used to accurately predict soot emis-sion of a turbo-charged diesel engine in different opening ranges of waste-gate (ORWG) [7].

On the other hand, there is another modelling approach called as adaptive neuro fuzzy inference system (ANFIS) which combines the benefits of ANNs and fuzzy logic. ANFIS modelling is very powerful technique with the ability of interpretable if-then rules [8]. Isin and Uzunsoy presented fuzzy logic-based prediction method to reveal the performance and emission characteristics of a single cylinder spark ignition (SI) engine, which uses different fuel mixtures [9]. Ozkan et al. used ANFIS to estimate the effect of methanol mixtures in different proportions on emission and performance of the motor [10]. Al-Hinti et al. used a neuro-fuzzy interface system to study the effect of boost pressure on the efficiency, brake mean effective pressure (BMEP), and the brake specific fuel consumption (BSFC) of a single cylinder diesel engine.

\footnotetext{
${ }^{*}$ Corresponding authour

Email: etosun@cu.edu.tr (E.Tosun)

$\S$ This paper was presented at the IMSEC-2016
} 
Results of their study showed that the ANFIS technique can be used adequately to identify the effect of boost pressure on the different engine characteristics.

In this study, experimental studies were taken from the study of Ozgur [12]. He investigated effects of addition of oxygen containing nanoparticle additives to diesel and biodiesel fuels on diesel and biodiesel fuel properties and effects on diesel engine performance and emissions. This study aims to predict exhaust emissions of diesel engine by various approaches as regression analysis, ANN, ANFIS. Finally, performances of models were determined by comparing experimental values and the best estimation technique was stated.

\section{MATERIALS AND METHODS}

\subsection{Experimental Studies}

Engine performance tests were performed on a commercial four cylinder, four-stroke, naturally aspirated, water-cooled direct injection compression ignition engine. Engine gives $89 \mathrm{~kW}$ maximum power at $3200 \mathrm{rpm}$ and $295 \mathrm{Nm}$ maximum torque at $1800 \mathrm{rpm}$ engine speed. Before the tests, the engine was operated for 15 minutes with diesel fuel to reach the operation temperature. A hydraulic dynamometer was used for determination of torque output. TESTO $350 \mathrm{XL}$ gas analyzer was used to measure exhaust emissions. Emission data was collected by the help of a computer program. Measurement accuracy of the gas analyzer is $\pm 10 \mathrm{ppm}$ for $\mathrm{CO}, 1 \%$ for $\mathrm{CO}_{2}$ and $\pm 1 \mathrm{ppm}$ for NOx. Measurement capacity of the device is 0-10000 ppm for CO, 0-50\% for $\mathrm{CO}_{2}$ emission and 0-3000 ppm for NOx. The speed sensor used to detect prime mover speed is the magnetic pickup (MPU). When a magnetic material (usually a gear tooth driven by the prime mover) passes through the magnetic field at the end of the magnetic pickup, a voltage is developed. The frequency of this voltage is translated by the speed into a signal which accurately depicts the speed of the prime mover. The Cetane number and indexes were measured by Zeltex ZX440 type device, which works under the close infrared spectrometer (NIR) principal. With the help of this principal the Cetane number measurement experiment became very fast and cheap with only $3 \%$ error compared to the time consuming expensive motor tests.

\subsection{Regression Analysis}

Regression analysis is commonly used to define quantitative relationships between a response variable and one or more explanatory variables [13]. Regression analysis can be applied to the data in linear and non-linear forms.

Linear relationship between dependent and independent variables can be expressed in form of [14]:

$$
Y=\beta_{0}+\beta_{1} X_{1}+\beta_{2} X_{2}+\cdots+\beta_{n} X_{n}
$$

where is dependent variable, to are equation parameters for linear relationship and to are independent variables.

Nonlinear regression is a form of regression analysis in which observational data are modeled by a nonlinear combination of the model parameters function. Non-linear relationship between dependent and independent variables can be expressed in form of [14]:

$$
\mathrm{Y}=\mathrm{a}_{0}\left(\mathrm{X}_{1}^{\mathrm{a}_{1}}\right)\left(\mathrm{X}_{2}^{\mathrm{a}_{2}}\right) \cdots\left(\mathrm{X}_{\mathrm{n}}^{\mathrm{a}_{\mathrm{n}}}\right)
$$

where is dependent variable, to are equation parameters for non-linear relationship and to are independent variables.

\subsection{Artificial Neural Network}

Artificial neural networks inspired by biological neural networks. They behave like human brain. As the brain, ANNs consist of many small, interconnected units [15]. These units called as neuron. A typical biological neuron was shown in Fig. 1.

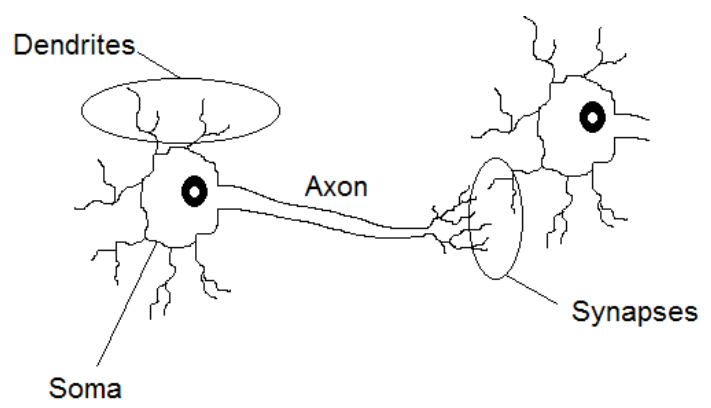

Figure 1: A typical biological neuron. 


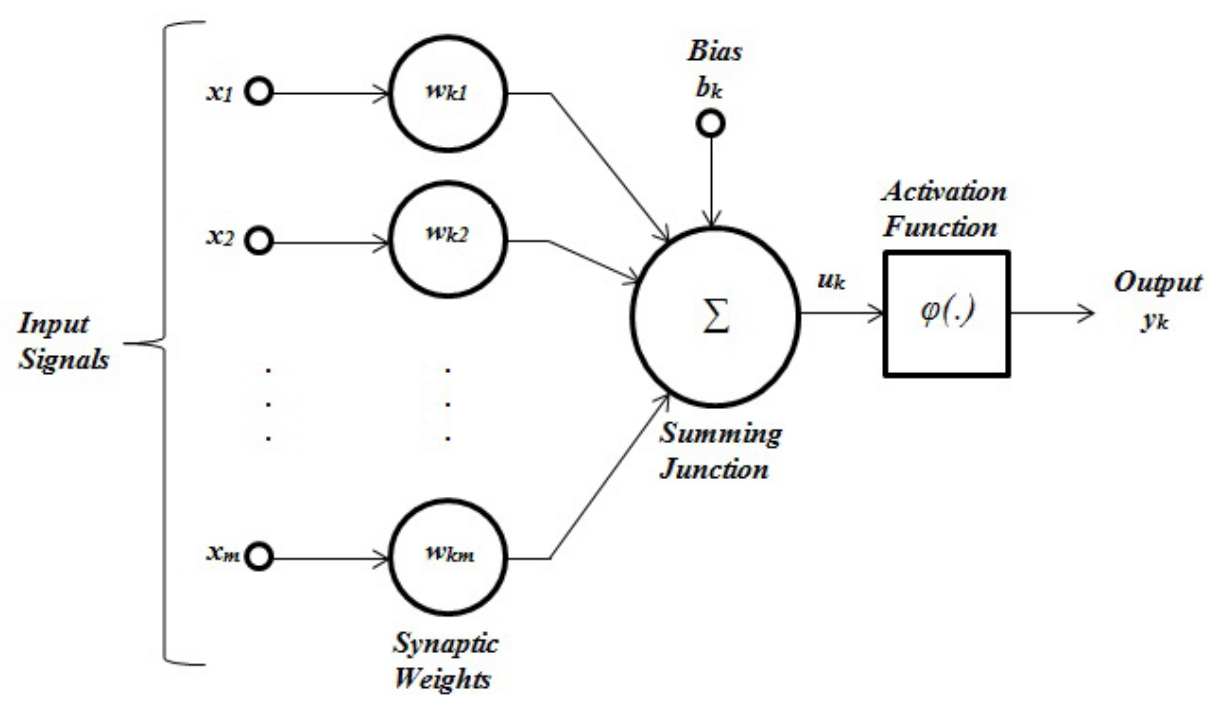

Figure 2: Block diagram of model of ANN neuron [16].

Haykin stated mathematically that, we can describe a neuron $\mathrm{k}$ by the following equations [16]:

$$
\begin{aligned}
& u_{k}=\sum_{j=1} w_{k j} x_{j} \\
& y_{k}=\varphi\left(u_{k}+b_{k}\right)
\end{aligned}
$$

Bias, denoted by bk, has the effect of increasing or lowering the net input of the activation function. $\mathrm{x}_{1}, \mathrm{x}_{2}, \ldots, \mathrm{x}_{\mathrm{m}}$ are the inputs; $\mathrm{w}_{\mathrm{k1}}, \mathrm{w}_{\mathrm{k} 2}, \ldots, \mathrm{w}_{\mathrm{km}}$ are the weights of the neuron $\mathrm{k} ; \mathrm{u}_{\mathrm{k}}$ is the linear combiner output due to input signals; $\varphi($.$) is the$ activation function; $y_{k}$ is the output signal of the neuron.

\subsection{Adaptive Neuro Fuzzy Inference System}

Adaptive Neuro Fuzzy Inference System (ANFIS) is combination system of neural networks and fuzzy logic and it has been applied to various application areas and gives more accurate results with respect to conventional techniques [17]. In fuzzy logic, nonlinearity and complexity of modelling can be handled by rules, membership functions and inference processes [9]. ANFIS can construct set-of if-then rules with suitable membership functions to constitute input-output pairs [18].

Jang presented the basics of fuzzy inference system that uses neural network learning algorithm [18]. Fig. 3 shows the main architecture of ANFIS. In this figure, fuzzy inference system with two inputs (x,y) and one output (z) was considered. According to Takagi and Sugeno type inference system, following two fuzzy if-then rules has been supposed:

Rule 1: If $x$ is $A_{1}$ and $y$ is $B_{1}$ then $f 1=p_{1} x+q_{1} y+r_{1}$

Rule 2: If $x$ is $A_{2}$ and $y$ is $B_{2}$ then $f 2=p_{2} x+q_{2} y+r_{2}$

$\mathrm{x}$ and $\mathrm{y}$ are the input nodes, $\mathrm{A}$ and $\mathrm{B}$ are linguistic variables (small, large etc.) associated with this node function.

More detail about the layers of the structure can be found in the study of Jang [18].

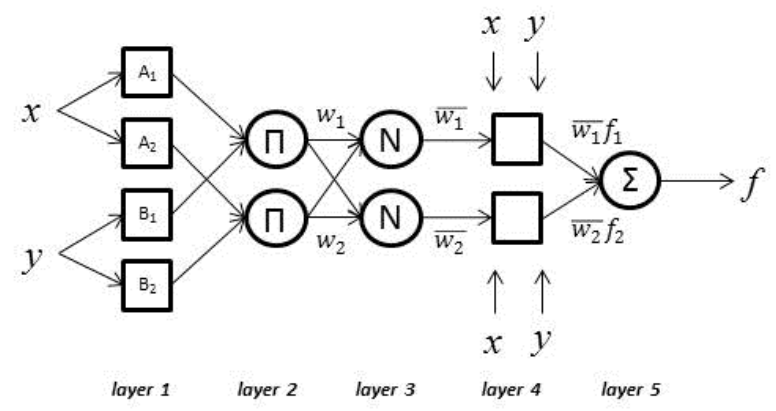

Figure 3: Architecture of ANFIS [18] 


\subsection{Details of Models}

\subsubsection{Regression Models}

SPSS software was used to perform regression analysis. It is well-known statistical and data management program. Cetane number $(\mathrm{CN})$ and engine speed $(\mathrm{rpm})$ was selected as predictor (independent) variables. Linear and non-linear form of regression analysis was evaluated separately. The results of the analysis were given in Table 1 .

Table 1 The results of regression analysis

\begin{tabular}{|c|c|c|c|c|c|c|}
\hline Y & \multicolumn{3}{|c|}{ Linear Regression } & \multicolumn{3}{c|}{ Non-linear Regression } \\
\hline CO & 109.993 & -1.228 & 0.099 & 2.818 & -0.089 & 0.636 \\
\hline NOx & 1288.84 & 5.489 & -0.247 & 11614.49 & 0.325 & -0.484 \\
\hline CO2 & 8.726 & 0.03 & -0.002 & 66.37 & 0.255 & -0.428 \\
\hline
\end{tabular}

\subsubsection{ANN Models}

Data set was generated by using the experimental results of previous study of Ozgur [12]. Then, the total data set was divided into two parts, training and testing data. Training part of data was for about $85 \%$ of total data. Remaining randomly selected $15 \%$ of total data was used to measure the estimation performance of model as testing.

Matlab software was used to perform ANN modelling. The ANN architecture was consisted of input, hidden and output layer as shown in Fig. 4.

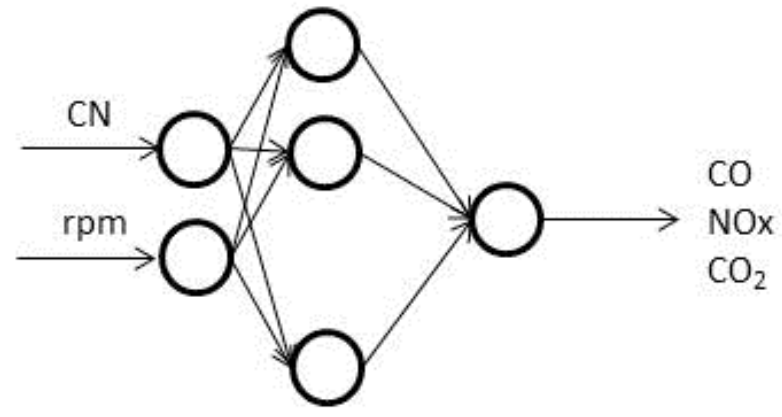

Figure 4: Architecture of ANN

Learning algorithm of the present study is Levenberg-Marquardt (LM) algorithm. Logistic sigmoid transfer function (logsig) and linear transfer function (purelin) were used in the hidden layers and output layer of the network as an activation function, respectively. There was an input layer, hidden layer and output layer. Table 2 shows the architecture of ANN models for each estimated parameters.

Table 2 Architecture of ANN models

\begin{tabular}{|c|c|c|c|c|}
\hline Estimation & Learning Algorithm & ANN Structure & Hidden Layer Transfer Function & Output Layer Transfer Function \\
\hline CO & LM & $2-30-1$ & $\operatorname{logsig}$ & purelin \\
\hline NOx & LM & $2-21-1$ & logsig & purelin \\
\hline CO2 & LM & $2-19-1$ & $\operatorname{logsig}$ & purelin \\
\hline
\end{tabular}

Since there was not a certain number of hidden layer neuron, number of hidden layer was determined by trial and error method. Suitable numbers of hidden layer neuron was supplied in above Table 2.

\subsubsection{ANFIS Models}

Matlab software was used to perform ANFIS modelling. As ANN modelling, the total data set was divided into two parts, training and testing data. Similar to determining the number of hidden layer neuron, there is no basic rule to define the number and type of membership functions for input parameters. It is an iterative process [17]. Table 3 shows the architecture of ANN models for each estimated parameters.

Table 3 Architecture of ANFIS models

\begin{tabular}{|c|c|c|c|}
\hline \multirow{2}{*}{ Estimation } & \multicolumn{2}{|c|}{ Input } & Output \\
\cline { 2 - 4 } & MF number & MF type & MF type \\
\hline $\mathrm{CO}$ & 44 & trimf & linear \\
\hline $\mathrm{NOx}$ & 44 & trimf & linear \\
\hline $\mathrm{CO} 2$ & 55 & trimf & constant \\
\hline
\end{tabular}




\section{RESULTS AND DISCUSSIONS}

In the following figures, testing periods of the each estimation method for $\mathrm{CO}, \mathrm{NOx}$ and $\mathrm{CO}_{2}$ were supplied.

In $\mathrm{CO}$ prediction, the worst estimation technique was linear regression with $9.41 \%$ error value with respect to experimental data. On the other hand, ANFIS is the best estimation technique with $4.89 \%$ error.

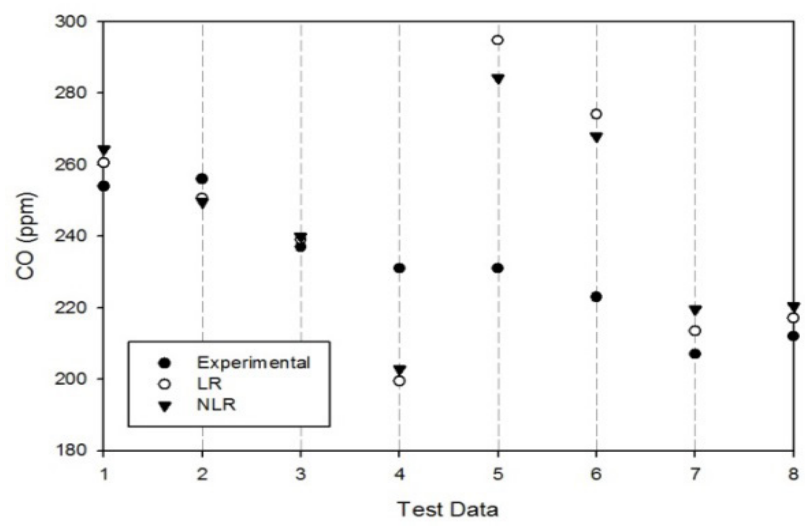

(i)

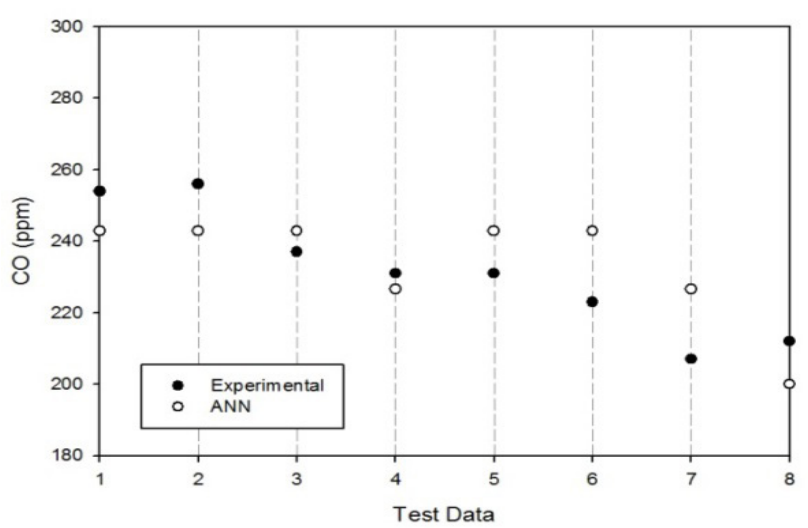

(ii)

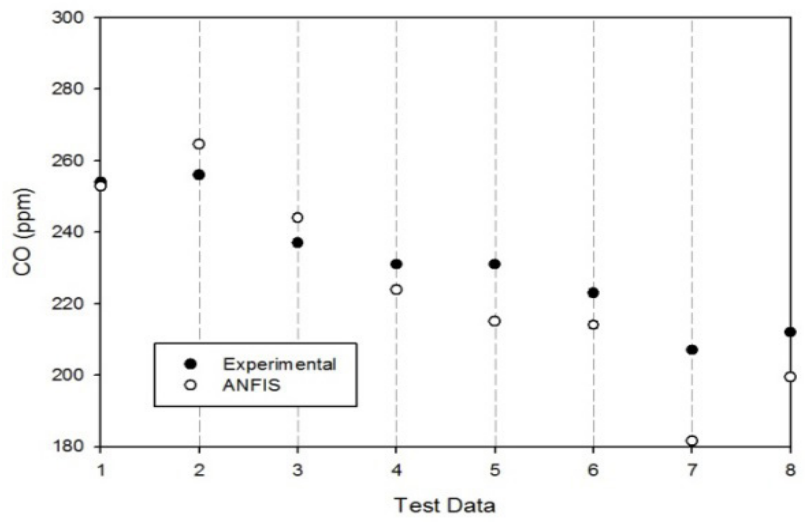

(iii)

Figure 5: Testing Results of (i) regression analysis (ii) ANN (iii) ANFIS for CO

In testing period of NOx prediction, linear regression is worst and ANFIS is best prediction method with $5.65 \%$ and $2.72 \%$ error, respectively. 


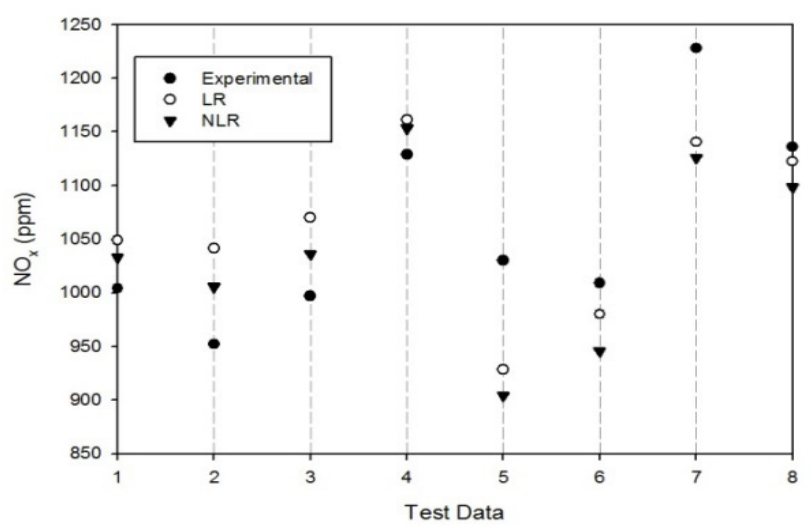

(iv)

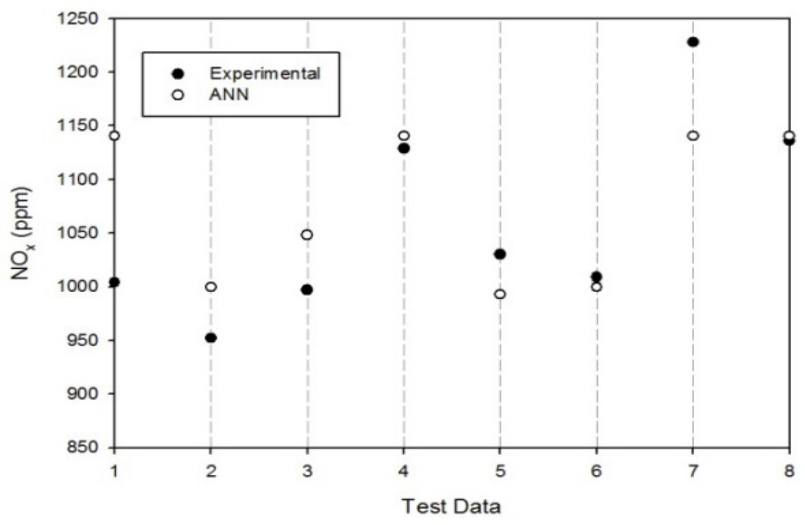

(v)

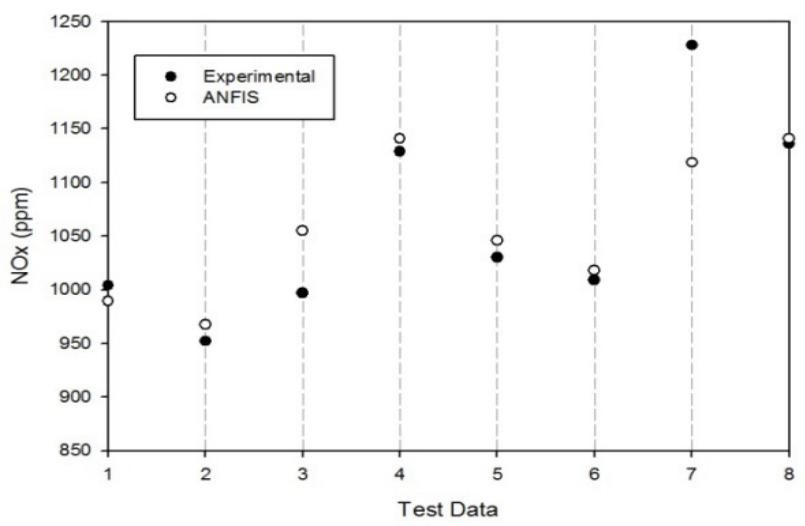

(vi)

Figure 6: Testing Results of (iv) regression analysis (v) ANN (vi) ANFIS for NOx

In $\mathrm{CO}_{2}$ prediction, the worst estimation technique was linear regression with $17.6 \%$ error value with respect to experimental data. ANFIS is the best estimation technique with $3.1 \%$ error. 


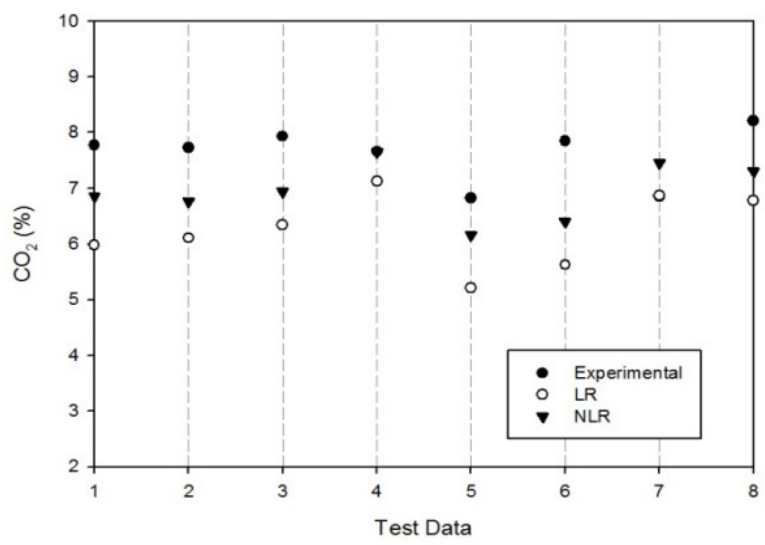

(vii)

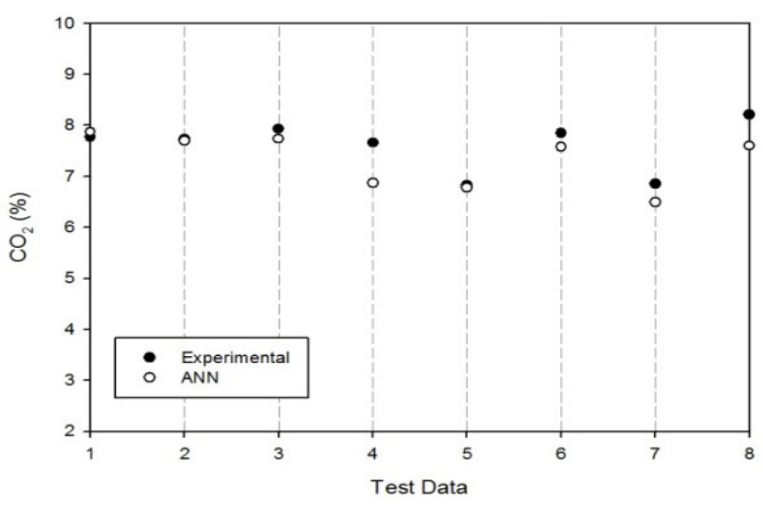

(viii)

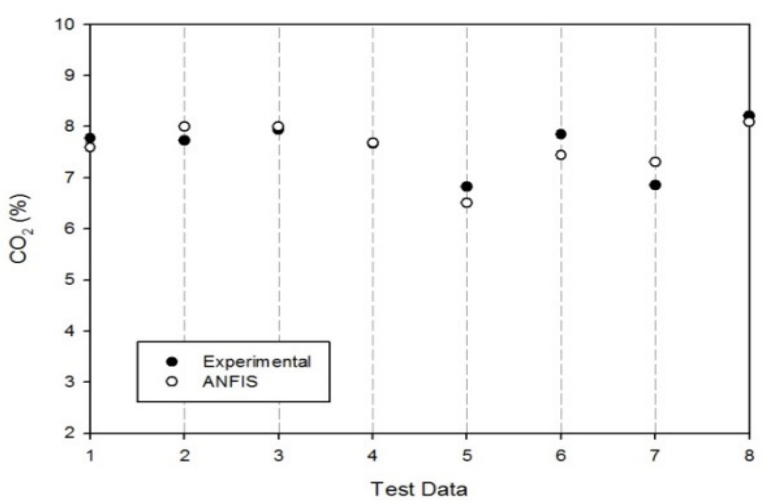

(ix)

Figure 7: Testing Results of (vii) regression analysis (viii) ANN (ix) ANFIS for $\mathrm{CO}_{2}$

Figs. 5, 6 and 7 showed the testing period of various modelling approaches for $\mathrm{CO}, \mathrm{NOx}$ and $\mathrm{CO}_{2}$ emissions, respectively. All predictions were compared with experimental values. Table 4 reveals the performance of both training and testing period of each model for each estimation parameter. Mean absolute percentage error (MAPE) was used as performance parameter. 
Table 4 MAPE values of models for both training and testing

\begin{tabular}{|c|c|c|c|}
\hline \multirow{4}{*}{$\mathrm{CO}$} & & \multicolumn{2}{|c|}{ MAPE (\%) } \\
\hline \multirow{4}{*}{} & & Training & Testing \\
\cline { 2 - 4 } & NLR & 16.19 & 9.41 \\
\cline { 2 - 4 } & ANN & 14.94 & 9.16 \\
\cline { 2 - 4 } & ANFIS & 1.5 & 5.39 \\
\hline \multirow{4}{*}{ NOx } & LR & 8.87 & 5.89 \\
\cline { 2 - 4 } & NLR & 9.84 & 5.59 \\
\cline { 2 - 4 } & ANN & 9.58 & 4.6 \\
\hline \multirow{4}{*}{$\mathrm{CO}_{2}$} & ANFIS & 1.82 & 2.72 \\
\hline & LR & 16.61 & 17.6 \\
\cline { 2 - 4 } & NLR & 13.33 & 10.63 \\
\cline { 2 - 4 } & ANN & 7.86 & 3.91 \\
\cline { 2 - 4 } & ANFIS & 4.12 & 3.1 \\
\hline
\end{tabular}

\section{CONCLUSIONS}

The purpose of this paper is to estimate emission of diesel engine by using cetane number of fuel and engine speed. In this respect, three different methods called as regression analysis, ANN and ANFIS were developed for prediction. Data were divided into two parts, training and testing. In training section model details were identified by using experimental data. In testing section, the accuracy and performance of the models were tested. For both emissions, LR and NLR gave worst results. It can clearly be seen from the Table 4. ANN models were more acceptable than regression results. Furthermore, ANFIS approach provided better performance then both regression analysis and ANN.

\section{REFERENCES}

[1] Tosun, E., Yilmaz, A.C., Ozcanli, M., and Aydin, K. (2014). Determination of effects of various alcohol additions into peanut methyl ester on performance and emission characteristics of a compression ignition engine. Fuel, vol. 126, pp. 38-43. 10.1016/j.fuel.2014.02.037

[2] Hussain, J., Palaniradja, K., Alagumurthi, N., and Manimaran, R. (2012). Effect of exhaust gas recirculation (EGR) on performance and emission characteristics of a three cylinder direct injection compression ignition engine. Alexandria Engineering Journal, vol. 51, no. 4, pp. 241-247. 10.1016/j.aej.2012.09.004

[3] Ismail, H.M., Ng, H.K., Queck, C.W., and Gan, S. (2012). Artificial neural networks modelling of engine-out responses for a light-duty diesel engine fuelled with biodiesel blends. Applied Energy, vol. 92, pp. 769-777. 10.1016/j.apenergy.2011.08.027

[4] Jahirul, M., Saidur, R., Masjuki, H., Kalam, M., and Rashid, M. (2009). Application of artificial neural networks (ANN) for prediction the performance of a dual fuel internal combustion engine. HKIE Transactions, vol. 16, no. 1, pp. 14-20.

[5] Yusaf, T., Yousif, B., and Elawad, M. (2011). Crude palm oil fuel for diesel-engines: experimental and ANN simulation approaches. Energy, vol. 36, no. 8, pp. 4871-4878. 10.1016/j.energy.2011.05.032

[6] Shanmugam, P., Sivakumar, V., Murugesan, A., and Ilangkumaran, M. (2011). Performance and exhaust emissions of a diesel engine using hybrid fuel with an artificial neural network. Energy Sources, Part A: Recovery, Utilization, and Environmental Effects, vol. 33, no. 15, pp. 1440-1450.

[7] Ghazikhani, M. and Mirzaii, I. (2011). Soot emission prediction of a waste-gated turbo-charged DI diesel engine using artificial neural network. Neural Computing and Applications, vol. 20, no. 2, pp. 303-308. 10.1007/s00521-010-0500-7

[8] Hosoz, M., Ertunc, H.M., Karabektas, M., and Ergen, G. (2013). ANFIS modelling of the performance and emissions of a diesel engine using diesel fuel and biodiesel blends. Applied Thermal Engineering, vol. 60, no. 1, pp. 24-32. 10.1016/j. applthermaleng.2013.06.040

[9] Isin, O. and Uzunsoy, E.U. (2013). Predicting the Exhaust Emissions of a Spark Ignition Engine Using Adaptive Neuro-Fuzzy Inference System. Arabian Journal for Science and Engineering, vol. 38, no. 12, pp. 3485-3493. 10.1007/s13369-013$0637-7$

[10] Özkan, İ.A., Ciniviz, M., and Candan, F. (2015). Estimating Engine Performance and Emission Values Using ANFIS/ANFIS Kullanılarak Motor Performans ve Emisyon Değerleri Tahmini. International Journal of Automotive Engineering and Technologies, vol. 4, no. 1, pp. 63-67.

[11] Al-Hinti, I., Samhouri, K., Al-Ghandoor, A., and Sakhrieh, A. (2009). The effect of boost pressure on the performance characteristics of a diesel engine: A neuro-fuzzy approach. Applied Energy, vol. 86, no. 1, pp. 113-121. 10.1016/j.apenergy.2008.04.015 
[12] Özgür, T. (2011) Investigation of nanoparticle additives to the biodiesel and diesel fuels for improvement of the performance and exhaust emissions in a compression ignition engine, M.Sc. Thesis, Mechanical Engineering, Cukurova University.

[13] Tabari, H., Kisi, O., Ezani, A., and Talaee, P.H. (2012). SVM, ANFIS, regression and climate based models for reference evapotranspiration modeling using limited climatic data in a semi-arid highland environment. Journal of Hydrology, vol. 444, pp. 78-89. 10.1016/j.jhydrol.2012.04.007

[14] Bilgili, M., Sahin, B., Yasar, A., and Simsek, E. (2012). Electric energy demands of Turkey in residential and industrial sectors. Renewable and Sustainable Energy Reviews, vol. 16, no. 1, pp. 404-414. 10.1016/j.rser.2011.08.005

[15] Krauss, G., Kindangen, J.I., and Depecker, P. (1997). Using artificial neural networks to predict interior velocity coefficients. Building and Environment, vol. 32, no. 4, pp. 295-303. 10.1016/S0360-1323(96)00059-5

[16] Haykin, S.S., (2001) Neural networks: a comprehensive foundation. Tsinghua University Press.

[17] Karimi, S., Kisi, O., Shiri, J., and Makarynskyy, O. (2013). Neuro-fuzzy and neural network techniques for forecasting sea level in Darwin Harbor, Australia. Computers \& Geosciences, vol. 52, pp. 50-59. 10.1016/j.cageo.2012.09.015

[18] Jang, J.S.R. (1993). Anfis - Adaptive-Network-Based Fuzzy Inference System. IEEE Transactions on Systems Man and Cybernetics, vol. 23, no. 3, pp. 665-685. Doi 10.1109/21.256541 